\title{
Effect of normal annealing and solution temperature on the microstructure and properties of TC4 bar

\author{
YANG Nan ${ }^{\mathrm{a},}{ }^{*}$, REN Yong ${ }^{\mathrm{a}}$, CUI Linlin ${ }^{\mathrm{a}}$, JU Biao ${ }^{\mathrm{a}}$, LEI Jinwen ${ }^{\mathrm{a}}$, LI Shaoqiang ${ }^{\mathrm{a}}$ \\ ${ }^{\mathrm{a}}$ Western Superconducting Technologies Co., Ltd., Xi'an 710018, China
} \\ *1549365362@qq.com
}

\begin{abstract}
$\underline{\text { Abstract }}$
The engine is one of the core components of aircraft, and the demand of mechanical properties of its raw materials is higher. The microstructure and properties of the raw materials could be improved by optimizing heat treatment systems. In this paper, the effects of annealing and solution aging on tensile properties of TC4 bar were compared, and the effect of solution temperature on microstructure and tensile properties of bar were studied. The results show that compared with annealing treatment, the tensile strength of bar is improved by $80 \mathrm{MPa}$ after solution aging treatment. And with the increase of solution temperature, the content of primary $\alpha$ phase is decreased, the content of secondary $\alpha$ phase is increased, the tensile strength is increased, and the maximum value reaches $1093 \mathrm{MPa}$. Finally, it is determined that the heat treatment system of bar is $965^{\circ} \mathrm{C} / 1 \mathrm{~h}, \mathrm{WQ}+720^{\circ} \mathrm{C} / 2 \mathrm{~h}, \mathrm{AC}$.
\end{abstract}

\section{Introduction}

TC4 titanium alloy is a kind of $\alpha-\beta$ two-phase titanium alloy, which contains $6 \%$ $\mathrm{Al}$ and $4 \% \mathrm{~V}$. It has excellent comprehensive mechanical properties, excellent thermal process plasticity and good weldability ${ }^{[1,2]}$. It can be used for a long time at $400{ }^{\circ} \mathrm{C}$, and its cost is relatively low. It is widely used in aerospace industry, such as blades, discs, casing of airplane engine fans and compressors, beams, joints and diaphragms in aircraft structures ${ }^{[3]}$.

TC4 titanium alloy is mainly used in fan disc, compressor disc and casing of airplane engine, and engine is the core component of aircraft, and the service environment is worse ${ }^{[4]}$. Therefore, higher requirements are put forward for the performance of materials used in airplane engine. Different heat treatments correspond to different properties of the alloy, so in order to obtain higher properties, this paper mainly studies the effects of different heat treatments on the structure and properties of TC4 titanium alloy, and determines the best heat treatment, so that it can meet the application requirements.

\section{Materials and experiments}

2.1 Experimental Materials 
TC4 titanium alloy ingot with good quality of $\$ 690 \mathrm{~mm}$ was forged on $45 \mathrm{MN}$ free forging press, and bars of $\Phi 210 \mathrm{~mm}$ are prepared. The microstructure of the bar forged in the two-phase zone is shown in Fig. 1. It can be seen that the grain boundary has been completely broken. The phase transition point of the bar is $1000^{\circ} \mathrm{C}$, and all the parameters of bar preparation both meet the standard of TC4 bar used in engine.

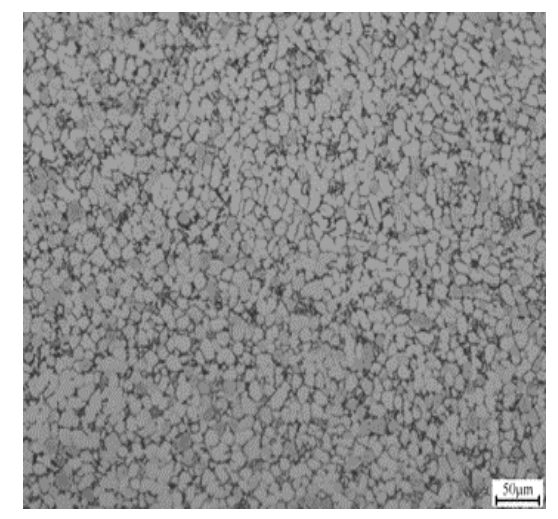

Fig.1 The microstructure after forging

\subsection{Experimental Method}

The $75 \mathrm{~mm}$ thick specimen was cut on the bar, and the $25 \times 25 \times 75 \mathrm{~mm}$ specimen was taken out by wire cutting at R/2 of the specimen. The $25 \times 25 \times 75 \mathrm{~mm}$ specimen were treated in the box resistance furnace according to different heat treatment. The specific heat treatment are shown in Table 1. Finally, room temperature tensile specimens were prepared on the specimens for mechanical properties testing. Tensile properties at room temperature were measured by universal material testing machine. Microstructure of specimens was observed by microscope. The corrosion solution of metallographic samples was $10 \% \mathrm{HF}+30 \%$ $\mathrm{HNO}_{3}+60 \% \mathrm{H}_{2} \mathrm{O}$.

Table 1 Sample number and corresponding heat treatment system

\begin{tabular}{|c|c|c|c|c|}
\hline Sample Number & $1 \#$ & $2 \#$ & $3 \#$ & $4 \#$ \\
\hline \multirow[t]{2}{*}{ Heat Treatment } & $780^{\circ} \mathrm{C} / 2 \mathrm{~h}, \mathrm{AC}$ & $930^{\circ} \mathrm{C} / 1 \mathrm{~h}, \mathrm{WQ}+$ & $950^{\circ} \mathrm{C} / 1 \mathrm{~h}, \mathrm{WQ}+$ & $965^{\circ} \mathrm{C} / 1 \mathrm{~h}, \mathrm{WQ}+$ \\
\hline & & $720^{\circ} \mathrm{C} / 2 \mathrm{~h}, \mathrm{AC}$ & $720^{\circ} \mathrm{C} / 2 \mathrm{~h}, \mathrm{AC}$ & $720^{\circ} \mathrm{C} / 2 \mathrm{~h}, \mathrm{AC}$ \\
\hline
\end{tabular}

\section{Results and discussion}


3.1 Effect of general annealing and solution aging treatment on microstructure and properties of bars

3.1.1 Effect of general annealing and solution aging treatment on microstructure of bars

The microstructure of conventional annealing treatment and solution aging treatment are shown in Fig.1. Fig.(a) is the microstructure of conventional annealing treatment. It can be seen that the microstructures are bimorphic, in which there are short rod-like $\alpha$ phase and equiaxed $\alpha$ phase, and there are lamellar secondary $\alpha$ phases in the $\beta$ transformed tissues. Fig.(b) is the microstructure of solution ageing treatment. It can be seen that the microstructure consists of equiaxed $\alpha$ phase and lamellar $\beta$ phase, and the morphology of primary $\alpha$ phase is equiaxed. This is due to the dissolution of $\alpha$ phase in $\beta$ matrix during solution process, and water cooling makes $\alpha$ phase that has not enough time to precipitate, resulting in the formation of supersaturated solid solution. However, the supersaturated solid solution is thermodynamically metastable. As a result, the $\alpha$ phase precipitates again and recrystallizes to form undistorted equiaxed grains during subsequent aging treatment. At the same time, compared with the Fig.(a) and Fig.(b), it can be found that the content of primary $\alpha$ phase in the annealed microstructure is more than that after solution aging treatment. This may be due to the higher solution temperature, which makes a large number of primary $\alpha$ phase dissolve in the $\beta$ matrix. 


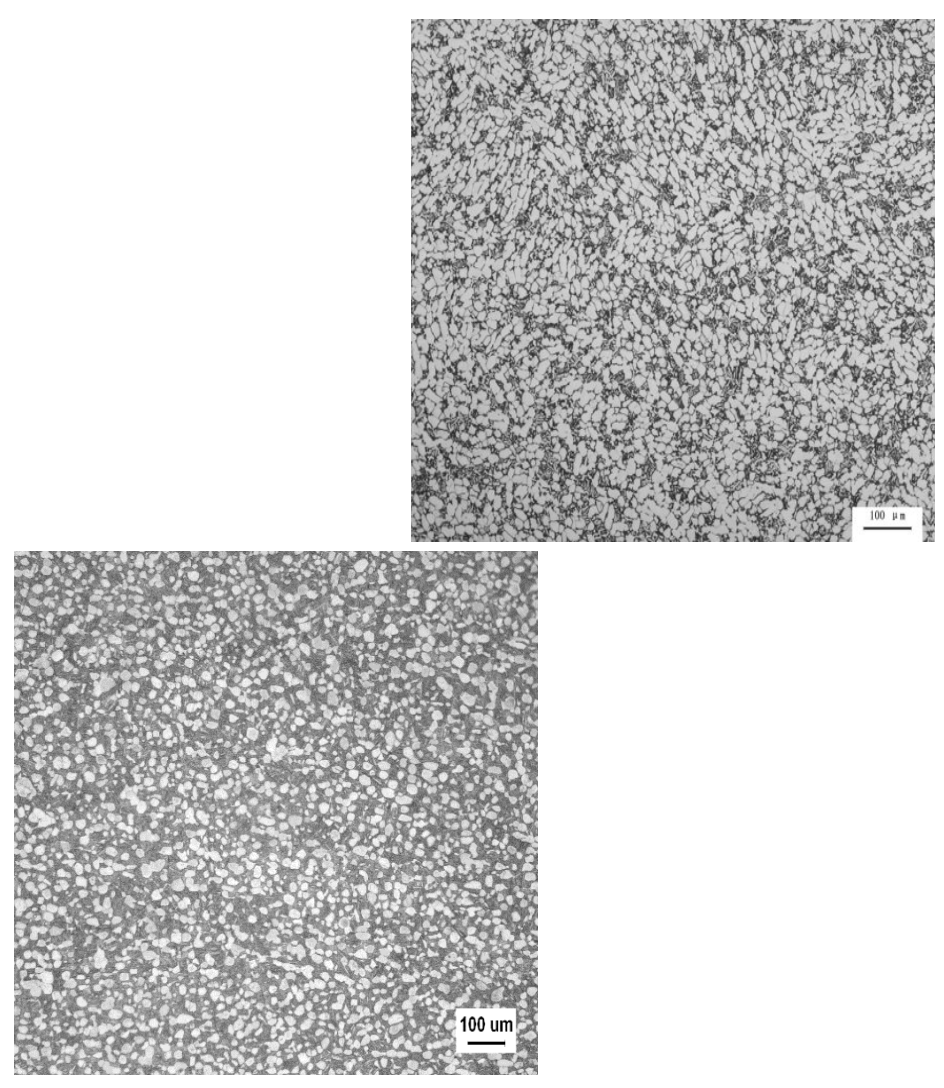

(a)Normal annealing
(b)Solution aging

Fig.1 The microstructure of normal annealing and solution aging

\subsubsection{Effect of general annealing and solution aging treatment on properties of bars}

Table 1 shows the room temperature tensile properties of the general annealed and solution aged respectively. It is obviously seen from table 1 that the highest tensile strength and yield strength of TC4 titanium alloy after general annealing are respectively $968 \mathrm{MPa}$ and $897 \mathrm{MPa}$. The highest tensile strength and yield strength of TC4 titanium alloy after solution ageing are respectively $1045 \mathrm{MPa}$ and $990 \mathrm{MPa}$. Compared with those after general annealing, the tensile strength and yield strength of TC4 titanium alloy after solution ageing are increased by about $80 \mathrm{MPa}$ and $90 \mathrm{MPa}$ respectively, But the plasticity of them is equivalent. The main reason is that the metastable phases, such as $\beta, \alpha^{\prime}$ and $\alpha^{\prime \prime}$, are obtained by rapid cooling during solution treatment, which are decomposed into dispersed $\alpha$ and $\beta$ phases during aging process. So the strength of the alloy is effectively improved ${ }^{[5]}$. At the same time, the equiaxed structure corresponding to the strength of the alloy is higher, and there are a 
large number of equiaxed grains in the structure after solution aging, so the strength of the alloy after solution aging is higher than that of the alloy after general annealing.

Table 1 The tensile properties of normal annealing and solution aging

\begin{tabular}{|c|c|c|c|c|c|}
\hline Number & Heat Treatment & $\mathrm{Rm} / \mathrm{MPa}$ & $\mathrm{Rp}_{0.2} / \mathrm{MPa}$ & $\mathrm{A} / \%$ & $\mathrm{Z} / \%$ \\
\hline \multirow[t]{2}{*}{$1 \#$} & $780^{\circ} \mathrm{C} / 2 \mathrm{~h}, \mathrm{AC}$ & 968 & 897 & 16 & 44 \\
\hline & & 937 & 872 & 14.5 & 40 \\
\hline \multirow[t]{3}{*}{$2 \#$} & $930^{\circ} \mathrm{C} / 1 \mathrm{~h}, \mathrm{WQ}+$ & 1045 & 969 & 13.5 & 37 \\
\hline & $720^{\circ} \mathrm{C} / 2 \mathrm{~h}, \mathrm{AC}$ & & & & \\
\hline & & 1038 & 990 & 11.5 & 35 \\
\hline
\end{tabular}

3.2 Effect of Solution Temperature on Microstructure and Properties of Bar

3.2.1 Effect of solution temperature on microstructure of bar

The microstructure of different solution ageing treatments are shown in Fig.2. It can be seen that the primary $\alpha$ phase is both equiaxed, and the content of primary $\alpha$ phase is about $43.8 \%$ after solution ageing treatment at $930^{\circ} \mathrm{C}$ and about $37 \%$ after solution ageing treatment at $950^{\circ} \mathrm{C}$. With the increase of solution temperature, the content of primary $\alpha$ phase in microstructure decreases obviously, and more primary $\alpha$ phase transform into $\beta$ phase, which increases the content of $\beta$ transformed structure. 


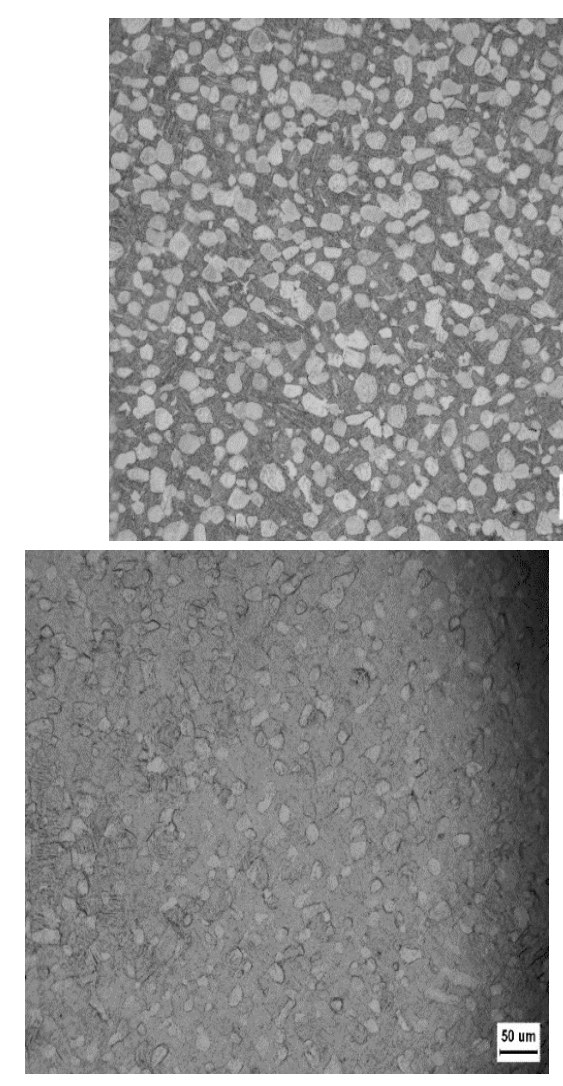

(a) $930^{\circ} \mathrm{C} / 1 \mathrm{~h}, \mathrm{WQ}+720^{\circ} \mathrm{C} / 2 \mathrm{~h}, \mathrm{AC}$

(b) $950^{\circ} \mathrm{C} / 1 \mathrm{~h}, \mathrm{WQ}+720^{\circ} \mathrm{C} / 2 \mathrm{~h}, \mathrm{AC}$

(c) $965^{\circ} \mathrm{C} / 1 \mathrm{~h}, \mathrm{WQ}+720^{\circ} \mathrm{C} / 2 \mathrm{~h}, \mathrm{AC}$

Fig.2 The microstructure of different solution temperature

\subsubsection{Effect of solution temperature on properties of bar}

Table 2 shows the tensile properties at room temperature after different solution and aging treatments. It is obviously seen from table 2 that when the solution temperature is $930^{\circ} \mathrm{C}$, the maximum strength is $1045 \mathrm{MPa}$, when the solution temperature is $950^{\circ} \mathrm{C}$, it is $1069 \mathrm{MPa}$, when the solution temperature is $965^{\circ} \mathrm{C}$, it is $1093 \mathrm{MPa}$. With the increase of solution temperature, the strength of the sample increases obviously, but the plasticity increases slightly. The main reason for the increase of strength is that with the increase of solution temperature, the content of primary $\alpha$ phase decreases and more transforms into $\beta$ phase. The increase of $\beta$ phase makes transform $\alpha$ phase increase after solution treatment, and the increase of $\alpha^{\prime}$ phase makes the strength of alloy increase. At the same time, more $\alpha^{\prime}$ phase decomposes dispersed $\alpha$ phase in the aging process, and the secondary $\alpha$ phase produced in the aging process plays a enhanced role ${ }^{[6]}$, so that the strength can be improved. Therefore, according to the results of tensile properties at room 
temperature after different solution aging treatments, it is sure that the optimum heat treatment for TC4 titanium alloy bars is $965^{\circ} \mathrm{C} / 1 \mathrm{~h}, \mathrm{WQ}+720^{\circ} \mathrm{C} / 2 \mathrm{~h}, \mathrm{AC}$.

Table 2 The tensile properties of different solution aging

\begin{tabular}{|c|c|c|c|c|c|}
\hline Number & Heat Treatment & $\mathrm{Rm} / \mathrm{MPa}$ & $\mathrm{Rp}_{0.2} / \mathrm{MPa}$ & $\mathrm{A} / \%$ & $\mathrm{Z} / \%$ \\
\hline \multirow[t]{3}{*}{$2 \#$} & $930^{\circ} \mathrm{C} / 1 \mathrm{~h}, \mathrm{WQ}+$ & 1038 & 990 & 11.5 & 35 \\
\hline & $720^{\circ} \mathrm{C} / 2 \mathrm{~h}, \mathrm{AC}$ & & & & \\
\hline & & 1045 & 969 & 13.5 & 37 \\
\hline \multirow[t]{3}{*}{$3 \#$} & $950^{\circ} \mathrm{C} / 1 \mathrm{~h}, \mathrm{WQ}+$ & 1066 & 985 & 13 & 46 \\
\hline & $720^{\circ} \mathrm{C} / 2 \mathrm{~h}, \quad \mathrm{AC}$ & & & & \\
\hline & & 1069 & 995 & 12 & 39 \\
\hline \multirow[t]{3}{*}{$4 \#$} & $965^{\circ} \mathrm{C} / 1 \mathrm{~h}, \mathrm{WQ}+$ & 1093 & 1017 & 14 & 43 \\
\hline & $720^{\circ} \mathrm{C} / 2 \mathrm{~h}, \quad \mathrm{AC}$ & & & & \\
\hline & & 1070 & 990 & 12 & 41 \\
\hline
\end{tabular}

\section{Conclusion}

1) Compared with the conventional annealing treatment, the content of primary $\alpha$ phase is less and the morphology of primary $\alpha$ phase is equiaxed after solution aging treatment. At the same time, higher tensile strength and yield strength are obtained, but the plasticity is basically the same.

2) With the increase of solution temperature, the content of primary $\alpha$ phase decreases, the content of $\beta$ transformed structure increases, and the tensile strength and yield strength also increase.

3) It is sure that the optimum heat treatment of TC4 titanium alloy bars in this paper is $965^{\circ} \mathrm{C} / 1 \mathrm{~h}, \mathrm{WQ}+720^{\circ} \mathrm{C} / 2 \mathrm{~h}, \mathrm{AC}$, and the maximum tensile strength obtained under this heat treatment is $1093 \mathrm{MPa}$.

\section{Acknowledgements}


I would like to extend my gratitude to my supervisor REN Yong and Lei Jinwen for their instructive advice and useful suggestions on my thesis.

\section{References}

[1] Wang Bo, Zeng Weidong, Peng Wenwen et al.The Development of Titanium Industry[J], 2014, 31(9):14-18.

[2] Qi Guangxia, Li Li an, Shi Likun et al.The Hot Working Process[J], 2014, 43(20):191-192.

[3] Peng Yanping, Zeng Fanchang, Wang Junjie et al.The Materials Engineering[J], 1997,36(10):3-6.

[4] Wei Xin, Zhao Xingdong, Li Changyong, et al. The Development of Chinese Materials[J], 2017, 36(7-8):588.

[5] Wang Qunjiao. The Nonferrous Metal Heat TreatmentTechnology[M].Beijing:Chemical Industry Press,2008.1.

[6] Gu Xiaohui, Liu Jun, Shi Jihong. The Heat Treatment of Metal[J]. 2011, 36(2):30-33. 